\title{
MATRIZ DEVEDOR-CREDOR E A FORMAÇÃO DO SUJEITO DE DIREITO: DA TROCA PRIMAL AO MERCADO
}

Prof. Tit. Dr. Celso Fernandes Campilongo

\begin{abstract}
Tese de Doutorado apresentado à Banca Examinadora do Programa de Pós Gradação em Direito, da Faculdade de Direito da Universidade de São Paulo, na área de concentração em Filosofia e Teoria Geral do Direito (DFD), sob a orientação do Prof. Tit. Dr. Celso Fernandes Campilongo.
\end{abstract}

UNIVERSIDADE DE SÃO PAULO

FACULDADE DE DIREITO

SÃO PAULO- SP

2018 
Autorizo a reprodução e divulgação total ou parcial deste trabalho, por qualquer meio convencional ou eletrônico, para fins de estudo e pesquisa, desde que citada a fonte.

\section{Catalogação da Publicação}

Faculdade de Direito da Universidade de São Paulo

Smilgys, Thaís Helena.

Matriz devedor-credor e a formação do sujeito de direito: da troca primal ao mercado. / Thaís Helena Smilgys; orientador Prof. Tit. Celso Fernandes Campilongo. São Paulo, 2018.

Tese (Doutorado) - Universidade de São Paulo, 2018.

1. Mercado. 2. Crédito-débito. 3. Sujeito de direito. I. Campilongo, Celso Fernandes. II. Smilgys, Thaís Helena. III. Título: Matriz devedor-credor e a formação do sujeito de direito: da troca primal ao mercado.

CDD 


\section{THAÍS HELENA SMILGYS}

\section{Tese De Doutorado}

\section{MATRIZ DEVEDOR-CREDOR E A FORMAÇÃO DO SUJEITO DE DIREITO: DA TROCA}

$$
\text { PRIMAL AO MERCADO }
$$

Autora: Thaís Helena Smilgys

Orientador: Prof. Tit. Dr. Celso Fernandes Campilongo

Este exemplar corresponde à redação final da Tese defendida por Thaís Helena Smilgys e aprovada pela Comissão Julgadora.

Data:

Assinatura:

Prof. Tit. Dr. Celso Fernandes Campilongo (Orientador)

Comissão Julgadora:

Profa. Dra. Lidia Reis de Almeida Prado

Prof. Dr. José Reinaldo Lima Lopes

Prof. Dr. Ricardo Mendes Grande

Prof. Dr. André Muniz Garcia

Prof. Dr. Henrique Garbellini Carnio

São Paulo, 15 de janeiro de 2018. 
A minha mãe, minha estrutura, Margareth.

À minha irmã, Bárbara.

Ao novo membro da família, Tutu. 


\section{AGRADECIMENTOS}

Agradeço, primeiramente, a meu orientador, Professor Celso Fernandes Campilongo, e à querida Professora Lídia Reis de Almeida Prado, ambos que por sua doçura, orientações e apoio me ajudaram a completar este caminho. Meus agradecimentos carinhosos ao amigo Prof. Ricardo Mendes Grande, que por mais de uma década me acompanha, orienta e que aceitou tão prontamente esta missão de estar presente neste trabalho final, revisando-o, criticando-o, melhorando-o. Agradeço-lhes imensamente por todos os ensinamentos de todas aulas lecionadas, que direta ou indiretamente, compõem esta Tese.

Agradeço, ainda, aos Professores Henrique Garbellini Carnio e André Muniz Garcia pela prontidão em ler, comentar e participar desta tese. Finalmente, mas nunca menos importante, Vinicius Spaggiari Silva, pelo companheirismo, pelo apoio, pelas discussões, por tudo que aprendemos juntos. 


\section{RESUMO}

O presente trabalho pretende analisar a formação do sujeito de direito, seja como conceito, seja como ideia. O viés da análise cuida de retomar a visão de Nietzsche, no que diz respeito à "origem" da sociabilidade humana, cunhada na obrigação legal entre devedor e credor (o que se chama "matriz devedor-credor"). Neste sentido, será necessário analisar a historicidade dos acontecimentos que transformaram o indivíduo em um animal capaz de realizar a promessa e a troca. Ao se revelar esta acepção propriamente nietzscheana da formação do sujeito, o trabalho cuidará de observar os movimentos jurídico-econômicos que transformaram o homem no sujeito, bem como demonstrar algumas possibilidades de conceber a relação entre tal sujeito e o funcionamento do direito e do mercado. Portanto, elaborar-se-á primeiramente uma nova concepção do sujeito por meio do referencial teórico contemporâneo e posteriormente se revelará o movimento histórico desta concepção, levando-se em conta a visão econômica da formação da sociedade.

Palavras-chave: sujeito de direito, mercado, troca, dívida. 


\begin{abstract}
The present work intends to analyze the formation of the subject of right, as either concept or idea. The path of the analysis takes care of resuming the Nietzsche' vision, with respect to the "origin" of human sociability, coined in the legal obligation between debtor and creditor (what is called "debtor-creditor matrix"). In this sense, it will be necessary to analyze the historicity of the events that transformed the individual into an animal capable of promise and exchange. When this proper nietzschean meaning of the formation of the subject is revealed, the work will take care of observing the juridicaleconomic movements that transformed the man in the subject, as well as to demonstrate some possibilities of conceiving the relation between this subject and the operation of the right and the market. Therefore, a new conception of the subject will be elaborated first by means of the contemporary theoretical reference and later the historical movement of this conception will be revealed, taking into account the economic vision of the formation of the society.
\end{abstract}

Keywords: subject of law, market, exchange, debt. 


\section{RIASSUNTO}

Il presente lavoro intende analizzare la formazione del soggetto del diritto, come concetto o idea. Il pregiudizio dell'analisi si occupa di riprendere la visione di Nietzsche, rispetto alla "origine" della socievolezza umana, coniata nell'obbligo giuridico tra debitore e creditore (ciò che viene chiamato "matrice debitore-creditore"). In questo senso, sarà necessario analizzare la storicità degli eventi che hanno trasformato l'individuo in un animale capace di realizzare la promessa e lo scambio. Quando si rivelerà questo significato nietzschiano della formazione del soggetto, l'opera si prenderà cura di osservare i movimenti giuridico-economici che hanno trasformato l'uomo nella materia, oltre a dimostrare alcune possibilità di concepire la relazione tra questo soggetto e l'operazione del diritto e del mercato. Pertanto, una nuova concezione dell'argomento sarà elaborata prima per mezzo del riferimento teorico contemporaneo e più tardi il movimento storico di questa concezione sarà rivelato, tenendo conto della visione economica della formazione della società.

Parole chiave: soggetto del diritto, mercato, scambio, debito. 


\section{SUMÁRIO}

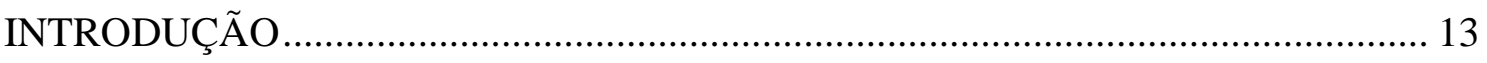

I. O SUJEITO DA TRADIÇÃO METAFÍSICA E SUA POSIÇÃO NO DIREITO . 26

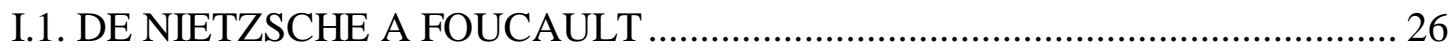

I.2. A POSSIBILIDADE PSICOLÓGICA DO SUJEITO: CRIAÇÃO DA

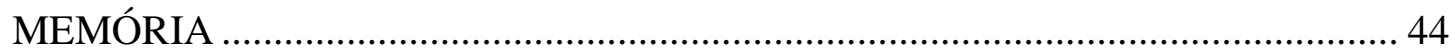

II. DO CORPO MORTO DA METAFÍSICA À HISTÓRIA ....................................... 84

II.1. PARA ALÉM DA LIBERDADE E DO CONTRATO …................................. 84

II.2. A PLAUSIBILIDADE HISTÓRICA DO SUJEITO ....................................... 106

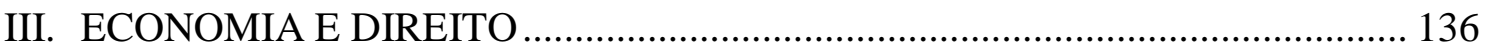

III.1. DA TROCA AO PODER E DO PODER À DIVIDA .................................... 136

III.2. IMPUTAÇÃO E MERCADO _................................................................ 160

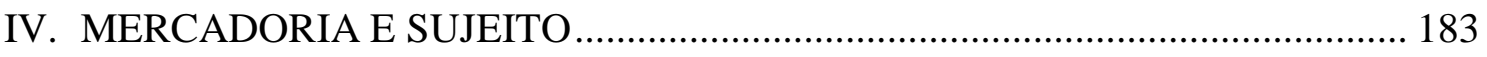

IV.1. A REFLEXÃO NIETZSCHEANA....................................................... 183

IV.2. NIILISMO E DÍVIDA: A RADICALIZAÇÃO DO PROCESSO ............. 201

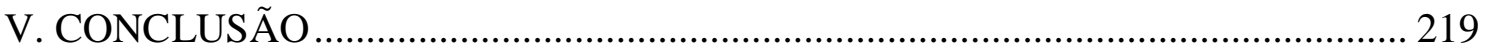

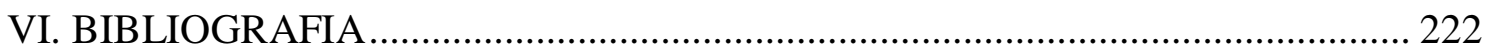




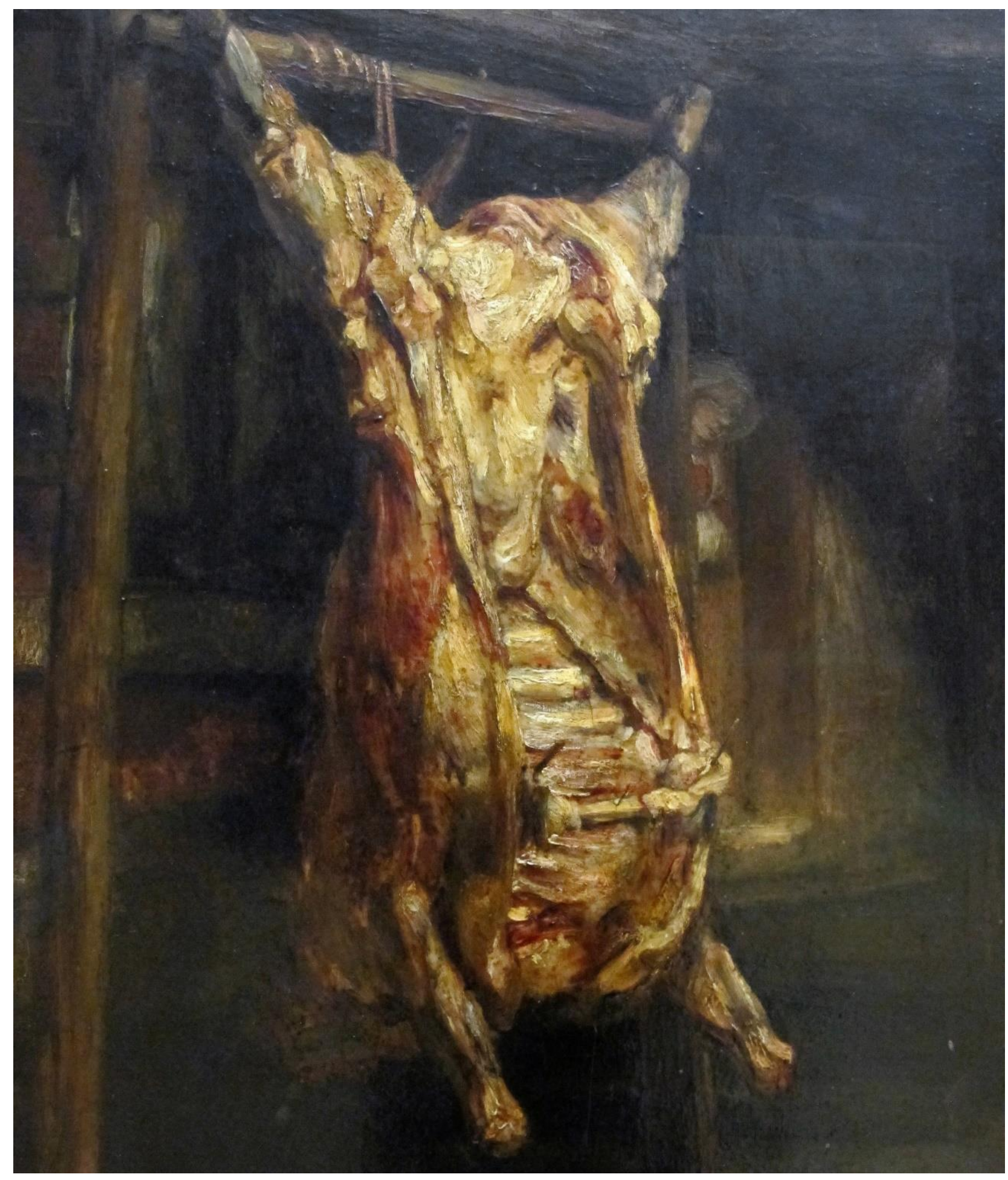

Geslachte os, 1655

Rembrandt Harmenszoon van Rijn 


\section{INTRODUÇÃO}

É como um sutra diz: "Quando não pagamos as coisas que pedimos emprestado, nosso pagamento torna-se o de renascer como um cavalo ou um boi". "O devedor é como um escravo, o credor é como um mestre". Ou novamente: "um devedor é um faisão e seu credor um falcão". Se você está em situação de ter concedido um empréstimo, não imponha uma pressão irracional ao seu devedor para reembolso. Se você fizer isso, você vai renascer como um cavalo ou um boi e ser posto para trabalhar para ele que estava em dívida com você, e então você vai pagar muitas vezes. (GRAEBER, 2011)

A carcaça de Rembrandt retratada no quadro "Geslachte os" denota a transposição do estado vital para o estado do corpo morto, o resto dos atos mercantis de criar o animal e matá-lo, de induzir a vida e eliminá-la, a fim de suprir o gosto e a biologia do humano, deste humano que, porque tornado elemento destacado da natureza, tem sobre ela prevalência, primeiro de potência, depois de razão, e hoje de niilista abstração na forma de valoração e operação mercantis. O quadro, contudo, o expressa em uma forte tensão, perceptível, de um lado, no retomar vívido da carne e das entranhas na forma de uma vida simbólica, que, embora remeta a um vivido pretérito, por um Rembrandt já morto há algumas centenas de anos, permanece criando seus efeitos pelo tempo, o que denota que, de outro lado, tal carcaça, tornada arte (sublimação do útil ${ }^{1}$ ), espreita o homem, que, em sua certeza de si, padeceu, nos séculos passados de lá para cá, como expectador de sua mortalidade, não só como espectador de uma mortalidade articulada qualquer (como a de quem sabe que vai morrer), mas como uma composição corpórea que, colmatada aos laivos da morte em vida, da negação de seu corpo em tamanha demasia alinhada com a operada no recortar da carne do animal que mesmo a sua carne parece expressa na imagem.

O homem já não pode comer o corpo dos homens, como o assevera Bataille ${ }^{2}$, mas o movimento que assim alcançou tal "possibilidade civilizatória” não o eximiu do recortar

\footnotetext{
${ }^{1}$ Para Campioni, tanto para Nietzsche, quanto para Coli, a arte possibilita a expressão da energia vital, grande estimulante da vida e permite a conexão da arte com o fundo animal da existência. A arte é capaz de expremir o fundo metafísico da realidade, a música, portanto é essencialmente uma suspensão do conceito ou “ jogo contra o regime de necessidade fenomenal”. CAMPIONI, 1992, p. 39.

${ }^{2}$ Desta forma, foi um passo, mas não somente um passo, que um homem escravizasse os outros, fazendo de seu semelhante coisa, possuída, ingerida, assim como o animal ou a planta. Mas o fato de que o homem tornou-se de outro homem resultou nesta repercussão: o senhor perante o qual o escravo tornou-se a coisa - é o soberano - retirou-se da comunhão, quebrando a comunicação dos homens entre eles. A ofensa do soberano à regra comum começou o isolamento do homem, a sua separação em partes que não poderiam ser reunidas senão raramente a partir de então, talvez nunca mais. BATAILLE, 1973, p. 153/154.
} 
das espadas sobre sua pele. E é aí que a estrutura do sujeito entra em ação. Esta possibilidade foi a escravização do homem pelo homem, a criação de uma relação servil em que o seu semelhante é coisa possuída, ingerida, assim como o animal ou a planta. É, como diz Foucault ${ }^{3}$, a virada genealógica que permite desmascarar a tomada de poder sobre os corpos.

Ora, embora o pensamento jurídico e o político não podem justificar sua relação com o mercado a partir de um ponto de vista segundo o qual a extração de energia da matéria viva é o cerne de uma relação causal. A análise do poder deve ser feita por meio da inscrição da matéria viva, ou melhor, exemplificada em termos de troca contratual " $a$ constituição do poder político se faz, portanto, nessa série, nesse conjunto teórico a que me refiro, com base no modelo de uma operação jurídica que seria da ordem da troca contratual. Analogia, por conseguinte, manifesta, e que corre ao longo de todas essas teorias, entre poder e bens, o poder e a riqueza."4

Esta via de acesso ao fenômeno jurídico, por meio do contrato, mais do que eliminar a névoa de benevolência e boa vontade que se deposita dia após dia sobre os mais sinistros dos ajustes sociais escoimados no pensamento jurídico, eliminaria também os poderes imanentes às complexas cadeias metafísicas que distribuem as competências de extração de tais energias àqueles que deles se valem. Isto é, o presente trabalho tem como premissa retomar, o tempo todo, a perspectiva de que

\begin{abstract}
a formação do sujeito universal autônomo de Kant na verdade pretende a legitimação da normatividade da liberdade (pressuposto moderno da imputação jurídica) aos moldes da ciência: "o objetivo último da metafísica da natureza é servir de programa a priori da pesquisa científica. O propósito último da metafísica dos costumes é análogo: legislar a priori sobre a práxis humana e, desta feita, possibilitar a priori a resolução de todos os problemas - jurídicos e outros - que surgem do uso externo da nossa liberdade (das relações entre os livres arbítrios dos agentes humanos). ${ }^{5}$
\end{abstract}

A ideia de um indivíduo como núcleo e sobre o qual é imprimido o poder (sua possibilidade psicológica e plausibilidade histórica) como criação necessária (condição transcendental) lido sob as lentes da tradição platônica, judaico-cristã e kantiana ${ }^{6}$,

\footnotetext{
${ }^{3}$ Foucault: "O corpo - e tudo o que diz respeito ao corpo, a alimentação, o clima, o solo - é o lugar da Herkunft: sobre o corpo se encontra o estigma dos acontecimentos passados do mesmo modo que dele nascem os desejos, os desfalecimentos e os erros nele também eles se atam e de repente se exprimem, mas nele também eles se desatam, entram em luta, se apagam uns aos outros e continuam seu insuperável conflito." FOUCAULT, 2006, p. 14.

${ }^{4}$ FOUCAULT, 2002, p. 20.

${ }^{5}$ LOPARIC, 2003, p. 7-8.

${ }^{6}$ This is an old story, in Nietzsche's view, and because of its deeply rooted past he broadly strokes a portrait of the history of the form in various images - i.e. in truth, morality, the self, art, the genius and in a cornucopia of other assorted types. According to Nietzsche's narrative, the post-Hellenic requirement to
} 
formariam um tríptico representativo de "moralidade" o qual se revelará, na perspectiva genealógica, não como subjectum,

como uma espécie de núcleo elementar, átomo primitivo, matéria múltipla e muda na qual viria aplicar-se, contra a qual viria bater o poder, que submeteria os indivíduos ou os quebrantaria. Na realidade, o que faz que um corpo, gestos, discursos, desejos sejam identificados e constituídos como indivíduos, é precisamente isso um dos efeitos primeiros do poder. Quer dizer, o indivíduo não é o vis-à-vis do poder; é, acho eu, um de seus efeitos primeiros. O indivíduo é um efeito do poder e é, ao mesmo tempo, na mesma medida em que é um efeito seu, seu intermediário: o poder transita pelo indivíduo que ele constituiu. ${ }^{7}$

Neste sentido, também como aponta Stegmaier, a propósito de Nietzsche e Luhmann:

que um já existente sujeito científico se transformará em sujeito moral. E ele se tornará reconhecidamente paradoxal: ao invés de ser capaz de pensar a objetividade dos objetos na sua consciência empírica, com a ajuda dos "a prioris" transcendentais que transcendem o empirismo da consciência, o sujeito tem de se desubjetivar a si mesmo. Kant pensa os objetos como sujeitos desubjetivados e como o seu conceito de sujeito inclui ambos, o empírico e o transcendental, ele simultaneamente concede o paradoxo. ${ }^{8}$

Assim, a articulação do sujeito, desde sua criação até sua plausibilidade histórica, como proposto por Nietzsche, é antes o combate à verdade, como valor objetivo, isto é, é retomar a subjetividade como problema epistemológico, ou mais especificamente, retomar historicamente a perspectiva do sujeito.

Para Nietzsche, esta concepção, tida como inversão valorativa estabelecida pela metafísica (unidade, superioridade da alma, invariabilidade), cujo limite coincide com a

feign objectivity at all costs began with Socrates. Plato, then, turned it into a metaphysical conception, before the Christians amplified it with religious intensity. Finally, this imperative was given the stamp of scientific verifiability during and after the Enlightenment, with Kant and the positivists of the nineteenth century. By making forgetfulness concerning the articulation of the form a requirement of knowledge, however, the West has been misled, Nietzsche would argue, not only to alienate human agency from the concepts that measure our lives, but also to pessimistically reject earthly values. To be sure, the voices of mysticism that first commandeered this imperative attempted at the outset to expel the calculative impulse, causing the sciences to develop on their own, to grow strong and resentful, and to be guided only by their enmity for what cannot be verified through them. Even as the cold eye of calculation rejected the imperative to forget, the mere recognition of our own roles in the creation of standards has diminished our wills to create them. We are compelled, then, not to act in the way that is most essential to human flourishing, because such inactivity seems less bothersome and because it is easier to live, skeptically, by the assassin's credo ('there is no truth, everything is permitted') than to will to differ. In other times, however, we fail to create and to live by higher principles in the name of 'tolerance'. Both states of consciousness are symptomatic of the same weakness of the will, in Nietzsche's view, bringing similar consequences to modernity: if everything were indeed permissible, he has shown us, human potential would all but shrivel up and die. For these reasons, a large amount of intellectual energy in the twentieth century has been directed towards problems concerning alienation, identity, meaning and purpose - the same problems that Nietzsche had identified as facing modernity in the nineteenth century. The strategy for resolving such problems and for loosening the pincers of pessimism and skepticism begins with finding, creating or perhaps refining a paradigm that encourages the healthy development of societies and individuals. WILKERSON, 2006, p. 126.

${ }^{7}$ FOUCAULT, 2002, p. 36.

${ }^{8}$ STEGMAIER, 2015, p. 492. 
criação do sujeito transcendental, pois nele reside a verdade como valor, é um sintoma do desregramento fisiológico que se fazia presente com Sócrates e que se perpetuava à época de Nietzsche (e a qual, urge lembrar, ainda se perpetua):

\begin{abstract}
Aquele consensus sapientium - isto eu compreendia cada vez melhor - é o que menos prova que tinham razão naquilo sobre o que concordavam: prova, muito mais, que eles próprios, esses sábios dos sábios, concordavam fisiologicamente em algum ponto, para, de igual maneira, se colocarem negativamente ante a vida, e terem de se colocar assim. Juízos, juízos de valor sobre a vida, pró ou contra, nunca podem, em definitivo, ser verdadeiros: só tem valor como sintomas, só como sintomas entram em consideração - em si tais juízos são estupidezes. ${ }^{9}$
\end{abstract}

Ora, com Nietzsche, o sujeito não é mais o fundamento objetivo da verdade, mas é a extensão do método, é o que garante a validade do método, na medida em que o sujeito é ficção. Assim, esta ideia metafísica que consiste em determinar o sujeito como o próprio ponto fundamental da verdade é recolocada a partir de Nietzsche uma vez que "cada humanidade, cada povo, cada cultura tem o seu "a priori dos valores", a sua avaliação fundamental, em função da qual cada um se situa no plano da existência e vive a sua vida". ${ }^{10}$

Este sujeito necessário e universal, que no campo da ação prática se transforma no sujeito autônomo, isto é, da totalidade ética de Kant, é o sujeito metafísico cuja essência é unitária, racional e imutável. Tal sujeito da "tradição" não só aparece em Nietzsche, como crítica da necessária garantia da verdade, isto é, do conhecimento científico verdadeiro, como será o ponto de articulação de sua crítica moral, na medida em que pode-se assumir que a crítica à verdade científica é para Nietzsche, o combate à moral.

Particularmente relevante, portanto, entender o combate nietzscheano à verdade metafísica, atrelada a este ponto fundamental de estrutura que se chama sujeito, também à luz de sua crítica aos valores tradicionais segundo os quais é constituído, além das consequências para o direito, ou seja, a forma com que o direito deriva, deste sujeito metafísico, o sujeito de direito, no sentido que:

Esta ética foi unanimamente adoptada, quer pela filosofia idealista alemã anterior a Hegel, quer ainda pelos novos fundadores da ciência jurídica, Hugo, Feuerbach e Savigny. Em particular, Savigny tirou daqui a convicção de que o direito serve à realização da moral, não enquanto ele "dá execução aos seus comandos, mas enquanto garante a cada um o livre desdobramento da sua vontade individual"; de que, portanto, o direito "deve dominar ilimitadamente no seu domínio" e não ter que cumprir qualquer outra missão, nomeadamente

\footnotetext{
${ }^{9}$ NIETZSCHE, KSA 6, 68.

${ }^{10}$ FINK, 1983. p. 131.
} 
"a definição ética da natureza humana" (ou, por exemplo, "um bem-estar político-econômico, designado por felicidade pública"). Do mesmo modo, as definições de direito subjetivo de autonomia privada, de negócio jurídico e de vontade negocial dadas por Savigny correspondem à exigência posta por Kant daquela liberdade que pudesse coexistir com a liberdade de todos os outros. A ética da autonomia, que Kant fornecera à renovação da ciência jurídica por volta de 1800 , concebeu o direito privado como um sistema de esferas de liberdade da personalidade autónoma do ponto de vista moral. ${ }^{11}$

Assim, a necessidade, de na ciência moderna, construir este fundamento ou ponto de apoio (Halt) para Nietzsche não seria senão invenção que rebaixa a vida a um sistema inócuo e sem sentido de valores universais cujas espiritualização e neutralidade não deixariam de demonstrar, em qualquer instante, seu caráter niilista. Veja-se:

Porque devemos dizer que, já crítico da tradição filosófica escrita (a partir de Platão) e desdenhoso - com a exceção de Spinoza - da razão dos modernos, que ele considera como filha e mãe da intuição, Nietzsche era, acima de tudo, desdenhoso da baixeza em que caíra, segundo ele, a filosofia atual ("hospital poluído por doenças horríveis"), com sua lógica matematizante, com a sua razão construtiva e acomodante, com seu cientificismo limitado e presunçoso, com seu racionalismo discursivo, com seu espiritualismo barato e seu otimismo superficial. ${ }^{12}$

Como já indicado em outros trabalhos ${ }^{13}$, a tese continua a seguir a pergunta: “porque é necessário o juízo sintético a priori?"14, mas agora não no que diz respeito à estrutura do conhecimento jurídico, mas ao mecanismo de captura do indivíduo por meio da ideia de sujeito, isto é, significa afirmar que a apreensão da experiência sensível por meio das condições de possibilidade (intuições puras a priori, tempo e espaço) deve ser feita por meio da compreensão da significação histórica do sujeito, ao contrário da busca científica moderna ou da crítica. Em outros termos:

Ela deverá provocar um deslocamento e toda uma reinscrição dos valores de ciência e de verdade, isto é, de algumas outras também. Uma tal redistribuição deveria permitir definir a "figura" que continua necessariamente a dar o seu "signo" a um "conceito" depois da retificação, depois do abandono de tal modelo "que talvez seja, em suma, apenas uma metáfora". ${ }^{15}$

O questionamento acima, levado a termos, revela que o sujeito de direito, formalizado na modernidade, não é exercício da consciência sobre si mesmo, mas é

\footnotetext{
${ }^{11}$ WIACKER, 1995, p. 717.

12 Perché bisogna dire che, già critico della tradizione filosofica scritta (da Platone in poi) e sprezzante - a parte Spinoza - della ragione dei moderni, da lui ritenuta figlia e non madre dell'intuizione, egli era soprattutto disdegnoso della bassezza in cui era caduta, secondo lui, la filosofia attuale ("lazzaretto inquinato da morbi orrendi"), con la sua logica matematizzante, con la sua ragione costruttiva e accomodante, con il suo scientismo limitato e presuntuoso, con il suo razionalismo discettante, con il suo spiritualismo a buon mercato e con il suo ottimismo superficiale. GIAMETTA, 2007, p. 107/108.

${ }^{13}$ SMILGYS, T.H. Responsabilidade e Imputação. Genealogia do Direito. Dissertação de Mestrado. 2013.

${ }^{14}$ NIETZSCHE, KSA 5, p. 294.

${ }^{15}$ DERRIDA, 1991, p. 304.
} 
produto do exercício de poder que garante a subsistência da sociedade capitalista ocidental, isto é, mantém o socius ${ }^{16}$ e o $\operatorname{locus}^{17}$ permissivos do mercado, pois universaliza a troca. Isto é, o sujeito é o mecanismo de captura do indivíduo.

Exatamente neste ponto que a problemática do sujeito ligada ao corpo, revela as condições de possibilidade que se tomado como espaço de subjetivação é mecanismo propulsor de uma metafísica que ao mesmo tempo que o funda (funda o sujeito) e, ao funda a sociedade (funda a história).

A reelaboração do sujeito por meio da perspectiva do corpo, ou do "modelo do corpus", "é o Corpus Juris, coleção ou compilação de instituições, Digestos e outros Códices de todas as normas do direito romano. Não é nem um caos nem um organismo: o corpus é mantido, e não apenas entre os dois, mas em outro lugar. Ele é a prosa de outro espaço, nem abissal, nem sistemático, nem sepulto, nem fundamento. Este é o espaço do direito: a sua fundação rouba o seu lugar, o direito do próprio direito é sempre sem direito". ${ }^{18}$

Assim, muito embora haja captura do corpo físico, da carne do sujeito, será o modelo jurídico do corpo (no sentido de compilado de instituições, feixes institucionais) que será o ponto de articulação da história, pois a história do sujeito é a história das instituições jurídicas ou métodos de extração da verdade por meio das formas jurídicas (testemunho, inquérito, exame e controle) que, como apontado por Foucault:

\begin{abstract}
As condições políticas, econômicas de existência não são um véu ou um obstáculo para o sujeito de conhecimento, mas aquilo através do que se formam os sujeitos de conhecimento e, por conseguinte, as relações de verdade. Só pode haver certos tipos de sujeito de conhecimento, certas ordens de verdade, certos domínios de saber a partir de condições políticas que são o solo em que se formam o sujeito, os domínios de saber e as relações com a verdade. Só se desbaraçando destes grandes temas do sujeito de conhecimento, ao mesmo tempo originário e absoluto, utilizando eventualmente o modelo nietzscheano, poderemos fazer uma história da verdade. ${ }^{19}$
\end{abstract}

O presente trabalho, portanto, versa sobre tal ascensão e queda do homem. Sobre o regime de relações lógicas nos quais ele subsiste sem existir, assim como no regime de relações corpóreas no qual ele existe sem refletir a si mesmo. Um regime, diga-se desde logo, no qual a estrutura institucional (da filosofia, da economia e do direito) impingiulhe uma vida na qual retiraram todas as forças vivas de sua estrutura corpórea e legaram a ela os restos de seu funcionamento biológico possível diante da dinâmica das forças

\footnotetext{
${ }^{16}$ DELEUZE; GUATTARI, 2004, p. 15.

${ }^{17}$ IRTI, 2003, p. VII.

${ }^{18}$ NANCY, 2008, p. 52.

${ }^{19}$ FOUCAULT, 2005, p.27.
} 
impingidas por seus regimes de poder emanadores de seus programas, digramas, enunciados, consequentemente, sua mecânica tomada como lógicas pelas diversas formalizações "lógicas" a eles consentâneos, em especial, na modernidade.

Retomando a leitura de Foucault,

\begin{abstract}
Nietzsche afirma que não há ser em-si, como também não pode haver conhecimento em-si. E quando diz isso, designa algo totalmente diferente do que Kant compreendia por conhecimento em-si. Nietzsche quer dizer que não há uma natureza do conhecimento, uma essência do conhecimento, condições universais para o conhecimento, mas que o conhecimento é cada vez, o resultado histórico e pontual de condições que não são da ordem do conhecimento. O conhecimento é efeito ou um acontecimento que pode ser colocado sob o signo do conhecer. $\mathrm{O}$ conhecimento não é uma faculdade, nem uma estrutura universal. Mesmo quando utiliza um certo número de elementos que podem passar por universais, esse conhecimento será apenas da ordem do resultado, do acontecimento, do efeito. ${ }^{20}$
\end{abstract}

Assim, nesta leitura o sujeito de direito é produto de uma prática social que perpassa a história da subjetividade, pois ao contrário da tendência acadêmica que "consiste em procurar de que maneira as condições econômicas de existência podem encontrar na consciência dos homens o seu reflexo e expressão (...) que apresenta um defeito muito grave: o de supor, no fundo, que o sujeito humano, o sujeito de conhecimento, as próprias formas do conhecimento são de certo modo dados prévia e definitivamente, e que as condições econômicas, sociais e políticas da existência não fazem mais do que depositar-se ou imprimir-se nesse sujeito definitivamente dado" 21 , o trabalho tem como objetivo "mostrar como as práticas sociais podem chegar a engendrar domínios de saber que não somente fazem aparecer novos objetos, novos conceitos, novas técnicas, mas também fazem nascer formas totalmente novas de sujeitos e de sujeitos de conhecimento", 22 .

É, portanto, necessário dar um passo além (ou aquém): é antes da crítica moral que se deve reler a história. Qualquer tipo justificação moral "a priori" ou "a posteriori" deve ser colocada, no mínimo com ironia. Não se trata de fazer uma crítica ao estilo kantiano (e posteriores) e submeter os juízos ao tribunal de uma Razão elevada que é capaz de garantir a correspondência daquilo que se conhece e daquilo que existe, pois aos que imaginam que esta tese é crítica, se responde de imediato: não é. O que se tenta conectar é uma certa dependência (nada lógica, nada divina) entre a subjetivação

\footnotetext{
${ }^{20}$ FOUCAULT, 2005, p. 24.

${ }^{21}$ Idem, p. 8.

${ }^{22}$ Idem. Ibidem.
} 
(formação do sujeito) e os mecanismos da dívida. Ou melhor, como a prática social do contrato cunhou a ideia de sujeito de direito.

A tese então, em linhas gerais, busca historicamente o surgimento de um sujeito capaz de ser responsabilizado e revela que sua construção tem a ver com os mecanismos obrigacionais de pagamento. Não à toa, a Segunda Dissertação da Genealogia da Moral de Nietzsche $^{23}$ será repetida por diversas vezes neste trabalho, explicita ou implicitamente. Isso quer dizer que foi necessário construir e autonomizar uma ideia nada natural de que existe um ser tal, que por nele residir certas qualidades é possível ser responsabilizado. E isso é fundamental para que os senhores possam exigir o pagamento, isto é:

\begin{abstract}
O olho estava agora preparado para esta perspectiva: e, com aquela grotesca consequência que é peculiar ao pensar da antiga humanidade, que é difícil de por em movimento, mas que em seguida prossegue inexoravelmenye na mesma direção, logo se chegou, com a grande generalização ao "cada coisa tem seu preço; tudo pode ser pago" - o mais antigo e mais ingênuo canon moral da justiça, o início de toda a "bondade", de toda "equidade", de toda "boa vontade", de toda "objetividade" sobre a terra. Justiça, neste primeiro grau, é boa vontade, entre os que têm potência mais ou menos igual, de se acomodarem uns aos outros, de, por meio de um igualamento, voltarem a se "entender" - e, em referência aos que tem menor potência, coagi-los, abaixo de si, a um igualamento. $^{24}$
\end{abstract}

Fantasticamente o sujeito se elevou a tal grau que é desnecessária a existência metafísica de qualquer ser sobre-humano (ora, a religião pode finalmente na modernidade, se colocar no espectro da liberdade individual). Mais importante que crer em algo, é crer neste alguém, "a um homem que justifique o homem, a um caso feliz de homem complementar e redentor, para que em função dele se possa manter a firme crença no homem!"25

O sujeito levado ao limite permite com que o genocídio seja, não mais feito com bombas e armas, mas que se mate de fome, que afunde os indivíduos na dívida e na promessa de pagamento e que a frase "alguém tem que pagar" seja um princípio intransponível, "pois assim está: o apequenamento e igualamento do homem europeu aninha nosso maior perigo, pois essa visão cansa...(...) Aqui justamente está a fatalidade da Europa - com medo ao homem perdemos também o amor a ele, a veneração por ele,

\footnotetext{
23 "Nesta esfera, a das obrigações legais, está o foco de origem desse mundo de conceitos morais: "culpa", "consciência", "dever", "sacralidade do dever" - o seu início como o início de tudo que é grande na terra, foi largamente banhado a sangue". NIETZSCHE, KSA 5, p. 300.

${ }^{24}$ NIETZSCHE, KSA 5, p. 306.

${ }^{25}$ NIETZSCHE, KSA 5, p. 278.
} 
a esperança nele, e até mesmo a vontade dele. A visão do homem agora cansa - o que é hoje niilismo, se não é isso?...Estamos cansados do homem..." 26

Há de se contar uma história a contra pelo, e evidenciar uma nova história do sujeito é recontar a história do direito, ou nos dizeres de Jean-Luc Nancy,

\begin{abstract}
Mas esta é ainda a estrutura propriamente do olho por si mesmo, que leva dentro de si, como Descartes não poderia deixar de notar, "um buraco redondo pequeno que é a chamada pupila, e que parece tão preta no meio do olho, quando olhamos de fora". De fora - mas nós vimos o que se gostaria de ver da pupila a partir do interior: isto é, ver, simplesmente, e não ver a visão, ou melhor, ver o olho morto a partir de onde enxergamos. Ver o olho vivo é ver a máscara - é sempre ver a figuração, vislumbradora da verdade (contudo, neste buraco que se abre pode estar uma boca), o buraco. Veja a máscara, ela vem com os olhos: mascarando, Descartes já o tudo viu. ${ }^{27}$
\end{abstract}

Será justamente por isso que não será possível afirmar as relações anteriormente sedimentadas pela tradição, principalmente aquelas que nos remetem à origem dos direitos, como "a priori” da ação livre, porque o feixe ação-liberdade é apenas invenção “a posteriori” de uma justificação da existência do direito: será na força e na luta dos opostos, no sangue e nos códigos que se verá, neste trabalho, o surgimento do direito. Assim, a subjetividade ética é remodelada em termos de perspectiva do sujeito; é o sujeito que vê, a visão do sujeito, a visão da visão que cuidará de desmistificar a verdade, pois a verdade não é senão mito.

A história como nos foi dada, analisa o direito moderno (formalizado a partir da unificação dos Estados) como ordem segundo a qual "bastava o que definido, constitucionalmente, em relação à propriedade privada e à liberdade contratual, ao quanto, não obstante, acrescentava-se umas poucas outras disposições veiculadas no nível infraconstitucional, confirmadoras do capitalismo concorrencial, para que se tivesse composta a normatividade da ordem econômica liberal "28: o valor do direito, ou seja, o direito é valorado em termos de liberdade. Isto pode ficar mais bem demonstrado quando analisamos a crítica à corrente utilitária do contratualismo que busca uma autoconservação humana ligada a uma estabilidade de condutas e de estruturação da liberdade como valor universal.

Vale dizer: o perfil da liberdade- ou os perfis das liberdades, que ela se decompõe em inúmeras espécies: liberdade política, econômica, intelectual, artística, de ensino, de palavra, de ação, etc. é o definido pela ordem jurídica. Entre nós, no plano da Constituição de 1988, a liberdade é consagrada, principiologicamente, como fundamento da República Federativa do Brasil c como fundamento da ordem Econômica. Ao princípio dá concreção, a própria Constituição, nas regras (normas)

\footnotetext{
${ }^{26}$ NIETZSCHE, KSA 5, p. 278.

${ }^{27}$ NANCY, 1979, p. 90

${ }^{28}$ EROS GRAU, p. 72
} 
inscritas, v.g., no seu art. $5^{\circ}$, incisos Il, VI, IX, XIII, XIV, XV, XVI, XVII, XX e 206 II. $^{29}$

Ou ainda com Hegel, nos Princípios da Filosofia do Direito:

Daí provém que nem o universal tem valor e é realizável, sem o interesse e a consciência e a vontade particulares, nem os indivíduos vivem como pessoas privadas unicamente orientadas pelo seu interesse e sem relação com a vontade universal, deste fim são conscientes em sua atividade individual. O princípio dos Estados Modernos tem esta imensa força e profundidade: permitirem que o espírito da subjetividade chegue até a extrema autonomia da particularidade pessoal ao mesmo tempo que o reconduz à unidade substancial, assim mantendo esta unidade no seu próprio princípio. ${ }^{30}$

Razão é, assim, liberdade, e liberdade é equilíbrio, objetividade, possibilidade de coagiar a um igualamento dos que tem potências diferentes. Ficando indiscutido, no modelo moderno de verificação, que o liame jurídico obrigacional é, em meio a tal intersecção de razão e liberdade em seguro equilíbrio, também, e pode-se dizer sobretudo, autorização para o exercício de poder.

Assim, o direito moderno com sua portentosa abstração - em larga escala derivada da sobreposição entre pensamentos jurídico e matemático -, restou por forjar, já no século XIX, as estruturas lógicas da reflexão jurídica do direito enquanto direito do sistema econômico capitalista: suas ideias de liberdade, responsabilidade, contrato, etc.

Para tanto, sob o aspecto estritamente jurídico-filosófico, pode-se afirmar que se o realizou por meio de uma operação lógica amplíssima, isto é, passou-se a remeter tanto as operações jurídicas, como a constituição das organizações sociais ao homem racional, que, pressupunha-se, tem total onisciência sobre o que contrata, e absoluta possibilidade material de determinar os caminhos da vida política, podendo, assim, por conseguinte, auferir todos os proventos de tal razão, e, da mesma maneira, devendo ser responsabilizado por todas as falhas que comete em vista dela.

Do que resulta que, na superfície das relações concretas - pode-se dizer, nos elementos constituintes da racionalidade liberal, de seus elementos, funcionamento e clivagens - o exercício de potência de um indivíduo contra o outro - antes nítido nos ruinosos espetáculos de sangue deixam de existir segundo esta compleição, mas as estruturas lógicas determinadas por seu exercício, mantidas no seio do sistema obrigacional, continuam a exercer o papel de autorizar, na aparente neutralidade das relações obrigacionais guiadas pelos valores abstratos, o exercício do poder do credor, e

\footnotetext{
${ }^{29}$ EROS GRAU, 202.

${ }^{30}$ HEGEL, 1997, p. 225.
} 
isto, quase sempre, sem se considerar o objeto sobre o qual se imputa o liame obrigacional.

E tal desenvolvimento genealógico é, sem dúvida, um movimento conceitual de relevo, mas tem, da mesma maneira, uma razão prática para ser discutida, já que nesta perspectiva, o mercado é concebido sobre uma normatividade estritamente jurídica, que possibilita, por meio do liame obrigacional privado, o exercício da potência de certos indivíduos contra outros. Portanto, questionar tal estrutura é, ao mesmo tempo, questionar as possibilidades de normatização do mercado pelo direito, cuja promessa de pagamento, coage, esfacela, constrange e destrói o homem. O que fica evidente quando se observa que certas análises modernas e contemporâneas do sistema obrigacional reduzem a imputação do liame obrigacional a exercícios diretos do poder privado de um indivíduo, ou coletividade de indivíduos, contra outros indivíduos, ou coletividade de indivíduos. Sendo decorrência das leituras contemporâneas a necessidade de restringir tais poderes do credor contra o devedor quando isto resultar desproporcional segundo os critérios estritamente normativos do sistema jurídico. E isto exsurge com maior clareza quando em questão os efeitos dos cataclismos macroeconômicos sobre a tessitura social das sociedades contemporâneas.

No entanto, a partir de Nietzsche é possível contar uma nova história do sujeito, a partir da ideia de débito/crédito e com isso uma nova história do direito. Esta nova perspectiva pauta-se na análise da obra Genealogia da Moral do filósofo e filólogo Nietzsche, que em suma, propõe a precedência de uma formação obrigacional entre os indivíduos, (formação jurídica da civilização e não moral que visa a autoconservação), isto é, afirma hipoteticamente que as relações entre credor e devedor são a base da hominização, isto porque "sua idéia é clara: se há oposição entre ciência e arte, há continuidade entre ciência e moral (...) A ciência não está isenta de juízos de valor, mais ainda: é a moral que dá valor à ciência"31.

Com forte caráter antropológico e histórico a genealogia propõe que o engendramento moral do homem se deu por uma valoração da obrigação para pagamento. Daí porque a justificativa de aplicação do direito, quando tomado por um viés de escolha político-moral precedente, pautada no sistema piramidal propriamente kelseniano, ultrapassa a esfera do "a priori" e eleva-se (em sentido metafórico) ao "além de".

\footnotetext{
${ }^{31}$ MACHADO, 1999, p. 9.
} 
Esta elevação, por assim dizer, força a busca metafísica da justificativa de existência do direito que pode ser tomada por uma argumentação jusnaturalista mais explícita ou por uma derivação racional de categorias morais de uma argumentação positivista mais implícita, ou seja, ou se toca no plano espiritual do sumo Bem, ou se toca no plano de Bens objetivamente postos além da Constituição, tais como os Direitos Fundamentais. Ou uma ou outra argumentação, ambas se revelam aquém das aspirações almejadas neste trabalho, porque se pretendem além, se pretendem metafísicos clássicos. Contar a história do sujeito é contar, portanto, a história do corpus, do modelo do corpus jurídico, sua normatividade intrínseca a partir do feixe da troca, da promessa, do contrato. Como fica fácil intuir, o foco do presente trabalho, e, aliás, o cerne da (re)construção do sujeito em suas possibilidades é a história da dívida. Dívida esta que nasce como efeito desta luta cega do homem contra ele mesmo, ou seja, nasce como efeito da memória e de consequência, a possibilidade de responsabilizar, domesticar o animalhomem:

\begin{abstract}
Mas a ascensão da cultura exige uma ruptura com a "civilização" da domesticação. (...). Isso significaria que, por aquilo que é a Bildung, de nada serve subverter a organização social, se não educarmos (ou não o deixarmos se educar) um outro ser humano, uma outra "raça". "Chega um momento no qual o homem tem um excedente de força ao seu serviço: a ciência levou à escravização da natureza. $\mathrm{O}$ homem se beneficia, por sua vez, do lazer: para formar algo de novo, mais alto. Nova aristocracia". 32
\end{abstract}

É este caráter histórico-crítico que emana das leituras de Nietzsche e a tradição contemporânea da filosofia que permite a possibilidade de se repensar o valor do sujeito, seja em termos mais imediatos de moral (ou moralidade), seja, ainda, reflexamente em termos econômico-jurídicos. ${ }^{33}$ É também nesta superação do crivo obrigacional da dívida

\footnotetext{
${ }^{32}$ Em francês: D'où pourraient-ils venir, ces 'aristocrates', ces excédentaires assez libres pour se détacher de la décadence? De l'excès même de celle-ci, à coup sûr. C'est la seule réponse possible. Et c'est pourquoi les 'esprits libres' doivent être les derniers à vouloir arrêter la décadence. 'L'égalisation de l'avènement d'une culture supérieure n'est certainement pas impossible dans les conditions matérielles que prévoit Engels: cela, Nietzsche l'accorde. Mais l'essor de cette culture requiert une rupture avec la 'civilisation' de domestication. Une rupture que le 'socialisme' n'est nullement en mesure d'effectuer, puisque sa pratique n'a de sens que relativement aux significations que projettent la société qu'il critique et le type de pouvoir qu'il entend exercer à son tour...Il me semble que c'est dans le voisinage de cette idée (que retrouve aujourd'hui Cornélius Castoriadis) qu'il faut chercher à comprendre 1'aristocratisme' de Nietzsche. Nouvelle aristocratie. LEBRUN, 2002, p. 126.

${ }^{33}$ Com essa nova relação entre o artista e o espectador já estamos no círculo mágico do espetáculo. Para produzir o trauma, a imagem deve ser espetacular; então o artista é um ator, um histrião, como o Zarathustra de Nietzsche, que não hesita em se tornar bufão para ganhara prosélitos. É preciso obrigar o espectador a entrar no jogo, a esquecer o útil, o compromisso da vida cotidiana, a se doar sem censura ou ressalvas; como faz o ator, especialmente o ator autêntico, popular, o acrobata ou o malabarista, que deforma ou transforma seu rosto e seu gesto humanos para entrar numa dimensão diferente, onde seu eu se torna outro, e, tornando-se fenômeno ou espetáculo, se doa inteiramente ao mundo, e justamente por deixar de ser para si e começar a ser para outro realiza inesperadamente sua personalidade. ARGAN, 2010, p. 502.
} 
que será permitido deslocar os sentidos, fazer corromperem-se as marcas, desalinhar cada ponto de pressão das forças que denigrem a vida.

Tudo o que fora enunciado até aqui é somente o começo da análise. Isto é, somente com a ruptura total com uma precedência moral ao jurídico que podemos travar um diálogo com as problemáticas trazidas. Somente com esta constatação inicial da possibilidade de ver o mundo através dos olhos de arte $^{34}$ é que será possível uma crítica radical dos ideais ascéticos, enquanto em contradição insolúvel com a vida. Desta feita, retomaremos, a partir de Nietzsche o ponto de partida que "caracteriza-se por um problema estético-psicológico" 35 que passa pela análise histórico-interpretativa da gênese do homem civilizado e domesticado - a genealogia.

Quer dizer, perquire-se qual a constituição e funcionamento do sujeito de direito moderno, que, junto com o reconhecimento da autonomia volitiva formal humana, exige a expansão da potência dos titulares do poder contra aqueles que são meros sujeitos nas relações supostamente livres e igualitárias constituídas sob a égide do direito. Mostra-se, pois, a constituição do sujeito moderno a partir dos elementos segundos os quais houve sua constituição racional, à vinculação à ética e à moral, bem como ao direito e à estrutura lógico-sistemática do direito.

Ou seja, descrever-se-á de que maneira tal movimento de construção do sujeito moderno se desdobra num sistema de articulação de poderes de um indivíduo contra o outro, superficialmente elidida sob a forma de igualdade e liberdade. Destacando-se, em especial, o papel da violência na constituição e no funcionamento do regime sistêmico (tanto jurídico como econômico, em indissociável amálgama) de "trocas comerciais" desde sua primeva constituição até os dias atuais, e, de qual maneira tal estrutura de violências aparentemente inauditas, mas vastamente sentidas, é compreendida pela filosofia de Nietzsche, que, por consequência, colima efeitos materiais na compreensão dos capitalismos moderno e contemporâneo.

\footnotetext{
${ }^{34}$ É certo que, a praticar desse modo a leitura como arte, faz-se preciso algo que precisamente em nossos dias está bem esquecido. NIETZSCHE, KSA 5, p. 256.

${ }^{35}$ FINK, 1983, p. 19.
} 


\section{CONCLUSÃO}

Ah ... Rembrandt ... toda admiração por Baudelaire de lado - eu me atrevo a assumir, especialmente com base nesses versos .... que ele sabia mais ou menos nada sobre Rembrandt [...] Mas veja, você já olhou de perto o "boi" ou o interior de uma açougue no Louvre? Você não olhou de perto, e Baudelaire, infinitamente também não. (VAN GOGH. Letter to Emile Bernard, 1888)

Olhar atentamente para o charco, para a carcaça. É essa a reinvindicação da tese. O corpo morto estirado como a mercadoria para venda nos incomoda e deve incomodar. Não somente pelo sangue, pelas práticas violentas de tortura que são impressas a todo momento nos indivíduos. Não somente pelas práticas cruéis do abate da mercadoria. Mas é além do processo. É o niilismo radicalizado que faz emergir deste corpo morto a questão do poder. É somente após esse longo processo de crueldade histórico contado e elaborado em termos de força que podemos ver o que, nos dizeres de Van Gogh, Baudelaire e Bernard não viram, mas que Bacon identificou: a liberdade dos mortos ou a servidão voluntária.

Daí porque Bacon dialoga com Rembrandt e Velázquez ao retomar, na carne, pela carne, e para a carne, a problemática do poder, a problemática do sacrifício como processo disjuntivo da estrutura corpórea e conjuntivo na estrutura do poder. Não mais aparências, não mais condescendência, não mais representação nem da unidade nem da integridade. Tampouco repetição da certeza da soberania no observar dos olhos, da boca, da figura. A carne do potente está, necessariamente, na carne do servo. Se um dia se pode falar de um e outra num plano dourado da representação corpórea unívoca, faz-se mister, enfim, tratar tal delírio consoante seu correlato estatuto, inscrição, clivagem, regime: vivissecção, se é que, ainda, se pode falar de vida após o périplo entre o martírio mercantil de Rembrandt ter se tornado a evisceração brutal da vida pelo poder em Bacon. Leon Kossovitch:

Em Bacon, o corpo não é uma organização anatômica e, por extensão, objeto de canônica de proporções; não se pode conceber uma anatomia como estrutura e uma conexa proporcionalidade não havendo unidade de medida arquitetônica e centro de emoção, ausente rosto que vista a cabeça. Pois não há, para Deleuze, retrato em Bacon, apenas pintura de cabeças: desvencilhando- se do viso, a cabeça é o sem face, logo, o sem-espetáculo. Também, assim como a cabeça descarta uma fisionomia de suposição, a carne não é revestimento de osso, mas seu disjunto. Sendo o esforço tensão, a carne e o osso se articulam disjuntivamente na carne de açougue, indo cada qual para o seu lado ou, como precisa Deleuze, uma para baixo, o outro para cima. Reciprocamente exteriores, a carne é o que desce do osso, o qual se ergue como uma estrutura material em que aquela forçadamente evolui. A carne desce e, nietzschianamente, mostra-se ativa à maneira de Zaratustra, que se põe a pregar porque baixa à planície. O osso e a carne confrontam-se no local onde ocorre 
o corpo como peça de açougue; o conceito de local disjuntivo é o de bloco bruto, para Deleuze também na coloração azul e vermelha da carne. O osso repropõe para o corpo a estrutura de uma carne trapezista. Movimento de ameba e deslizamento pelo osso são modos do irrisório, que só a dupla acepção de lugar, de estaticidade e micromovimento pode produzir. ${ }^{394}$

É esta perspectiva ligada a visão dos corpos não como organização, mas como confronto espacial, que permite retirar desse campo apriorístico o sistema matricial da dívida tão caro à economia. Isto é, os conceitos de racionalidade econômica e dívida é, de fato, uma obra da política e um exercício de força. Neste sentido, a obra moral moderna - cuja formulação é realizada nos imperativos categóricos - nada mais é do que uma formulação normativa que colhe sua legitimidade da imemorial na fixação sangrenta das normas sociais no corpo.

A metáfora coloca algo do devedor sob o poder do credor. Mais especificamente, capturando-se, real ou metaforicamente, o corpo do devedor, sua mulher, sua liberdade ou mesmo sua vida, mas, em outras ocasiões, sua bem-aventurança, a salvação de sua alma sua paz no túmulo, e isto tudo veio a encontrar esteio no rigor lógico do cálculo, que passou a permitir "avaliações precisas, terríveis em suas minucias, avaliações legais de membros e partes do corpo". Como dizem Deleuze e Guattari "é a dívida, são os blocos de dívida abertos, móveis e finitos, esse extraordinário composto da voz falante, do corpo marcado e do olho apreciador" ${ }^{395}$ : então, não é necessariamente no âmbito da negociação, da troca, ou mesmo do contrato e da conduta que se estatui a dívida, mas no da metáfora pura que se dissemina, que ganha sentido de distensão próprias.

Toda a reflexão levantada nesta tese estabelece a dívida não somente como um elemento jurídico-positivo, mas sim como uma embreagem que permite a modulação da matriz devedor-credor. Portanto, com a tese, é possível observar a formação e surgimento do sujeito de direito no centro no processo de subjetivação e inscrição do corpo, a partir de práticas jurídicas e sociais - sujeito este que toma os contornos modernos a partir de relações entre credores e devedores.

Por esta abordagem específica, assim, a tese permitiu estabelecer os vínculos sob os quais as relações de troca (e econômicas) explicam o modo como se deu, historicamente, a hominização (i.e., a transformação do animal esquecidiço para outro, ao qual seja lícito fazer promessas, o animal-homem). Não só isso, mas somente com uma desconstrução do sujeito é possível entender como as práticas jurídicas, atravessadas

\footnotetext{
${ }^{394}$ KOSSOVITCH, 2003, p. 164.

395 DELEUZE; GUATTARI, 2004, p. 197.
} 
pelos elementos de uma troca primal, permitiram a emergência de uma nova forma de sujeito, o sujeito de direito, que formula e funciona a partir de uma racionalidade radicalmente histórica e social capaz de delimitar por si mesma seus eixos de significação a partir dos vetores de poder individual e social, sua diferença de potência a partir de outros sujeitos do mundo.

Quer dizer, mencionar que surgimento do homem "civilizado" - sempre responsável - é, de plano, questionar o "homem moderno" - sua consequência radicalizada, do alto de sua liberdade plenipotenciária, tornado devedor de tudo e de todos, apesar e contra a vida. E, por isso, fazer funcionar uma crítica que se fomenta nos interstícios de cada elemento lógico do Estado de Direito que funciona no Capitalismo pós-industrial. 


\section{BIBLIOGRAFIA}

AGAMBEN, Giorgio, Homo sacer: pt. 1. Stato di eccezione, pt. 2. Il regno e la gloria : per una genealogia teologica dell'economia e del governo, Einaudi, Roma, 1995.

ALFRED GELL. The Art of Anthropology. Ed. Eric Hirsch. London School of Economics Monographs on Social Anthropology. Vol. 67. New York: Oxford Press, 2006.

ALLIEZ, Eric, A Assinatura do Mundo, O que é a filosofia de Deleuze e Guattari, 34, 1995, Rio de Janeiro.

ARGAN, Giulio Carlo. Arte moderna. Trad. Denise Bottmann e Frederico Carotti. $2^{\mathrm{a}}$ ed., $4^{\mathrm{a}}$ reimpressão. São Paulo: Companhia das Letras, 2013.

ARNOLD, Thurman W., The Folklore of Capitalism, $3^{\mathrm{a}}$ ed., Oxford University Press, Bombay, 1938.

ALTHUSSER, Louis; BALIBAR, Étienne, Lire le Capital, vol. II, François Maspero, Paris, 1969, p.52.

BATAILLE, Georges. Maîtres ou esclaves? in BATAILLE, Georges, CEuvres Complètes II, Gallimard, Paris, 1970.

L'Expérience Intérieure. in BATAILLE, Georges, Euvres

Complètes V, Gallimard, Paris, 1973. La limite de l'utile. in BATAILLE, Georges, Euvres Complètes

VI, Gallimard, Paris, 1976-A.

Le don de soi. in BATAILLE, Georges, Euvres Complètes

VII, Gallimard, Paris, 1976-B.

BAUDILLARD, Jean. L'echange symbolique et la mort. Paris: Gallimard, 1976.

BEAUFRET, Jean. Heidegger et Nietzsche: le concept de valeur. In: Colloque de Royaumont Nietzsche, Colletion Critique: Le Editions Minuit, 1967.

BLOCH, Marc. A Sociedade Feudal. Trad. de Emanuel Lourenço Godinho. Edições 70, Lisboa, 1982.

BRAUDEL, Ferdinand, Le Jeux de l'Échange - Civilisation Matérielle, Économie et Capitalisme, Vol. 2, Armand Colin, Paris, 1979. , Le Temps du Monde - Civilisation Matérielle, Économie et Capitalisme, Vol. 3, Armand Colin, Paris, 1979. 
BRINZ, Alois von, Lehrbuch der Pandekten, Zweiter Band, Erlangen, 1879.

BOBBIO, Norberto. Direito e Estado no Pensamento de Emanuel Kant. Trad. Alfredo Fait. São Paulo, Editora Mandarim, 2000.

BOLTANSKI, Luc; CHIAPELLO. Ève Le nouvel esprit du capitalisme. Paris: Gallimard, 1999.

BOURG, Julian, Rousseau and the Terror: A Reassessment, in LAURITSEN, Holger Ross; THORUP, Mikkel, Rousseau and revolution, Continuum International Publishing Group, Londres e Nova Iorque, 2011.

CAMPIONI, Giuliano. Leggere Nietzsche. Alle origino dell'edizione Colli Montinari. Pubblicazioni del Seminario per le Scienze Giuridiche e Politiche dell'Universita' di Pisa. 1992.

CHAPPA, Romain. Le problème du sujet dans la philosophie de Nietzsche. Philosophy. 2008. In: HAL Id: dumas-00611468. http://dumas.ccsd.cnrs.fr/dumas-00611468.

COASE, Ronald Harry. The firm, the Market, and the Law, in COASE, Ronald Harry, The firm, the Market, and the Law, University of Chicago Press, Chicago, 1990.

COLLI, Giorgio. Filosofia Dell'Espressione. 2a ed. Milão: Adelphi Edizioni, 1969.

COMPARATO, Fábio Konder, Essai D'analyse Dualiste de l'Obligation en Droit Privé. Dalloz, Paris, 1964.

DELEUZE, Gilles; GUATTARI, Félix. O Anti-Édipo - Capitalismo e Esquizofrenia. Trad. Joana Moraes Varela e Manuel Maria Carrilho. Lisboa: Assírio \& Alvim, 2004. DELEUZE, G. Conversações. São Paulo: Ed. 34, 1992.

Foucault. Trad. Claudia Sant'Anna Martins. São Paulo: Ed. Brasiliense, 2005.

Lógica dos sentidos. Tradução de Luiz Roberto Salinas Fortes. São Paulo, Perspectiva, Ed. da Universidade de São Paulo, 1974.

. Francis Bacon: The logico of sensation. Trans. Daniel Smith. Minnesota: Minnesota Press, 2003.

DERRIDA, Jacques. De La Grammatologie. Paris: Les Editions de Minuit, 1967. Margens da filosofia. Trad. Joaquim Torres Costa; António M. Magalhães; Campinas: Papirus, 1991. . Spectres de Marx - L'État de la dette, le travail du deuil et la nouvelle Internationale, $1^{\mathrm{a}}$ ed., Paris: Galilée, 1993. . Força de Lei. $2^{\mathrm{a}}$ Ed. Martins Fontes, São Paulo, 2010.

DELEUZE, Gilles, Nietzsche et la Philosophie, 6 $6^{\mathrm{a}}$ ed., PUF, Paris, 1983. 
EHRLICH, Eugen. Fundamentos da Sociologia do Direito. Trad. René Ernani Gertz. Editora UnB, 1986.

EWALD, François État Providence. Paris: Grasset, 1986.

FERRARA, Francesco. Il Fallimento. $3^{\mathrm{a}}$ ed, Milão: Giuffrè, 1974.

FERREYRA, JULIÁN. L'ontologie $d u$ capitalisme chez Gilles Deleuze. Paris: L’Harmattan, 2010.

FLEISCHMANN, Eugène. Weber e Nietzsche. In: Cohn, Gabriel (org). Sociologia: para ler os clássicos. Rio de Janeiro: Livros Técnicos e Científicos, 1977.

FOUCAULT, Michel. Eu, Pierre Riviere, que degolei minha mãe, Minha irmã, e meu irmão - Um caso de parricídio do século XIX, Trad. Denize Lezan de Almeida. 5a , Edição 1991.

As Palavras e as Coisas. Trad. Salma Tannus Muchail. Martins Fontes, São Paulo, 2000. . A Verdade e as Formas Jurídicas, 2a edição, Rio de Janeiro, 2001. . Em Defesa da Sociedade, Martins Fontes, São Paulo, 2002. Microfísica do Poder. Trad. Lígia M. P. Vassalo, Rio de Janeiro: Edições Graal, 2006.

A arqueologia do saber. Trad. Luiz Felipe Baeta Neves. $7^{\mathrm{a}}$ edição/ $3^{\mathrm{a}}$ reimpressão; Rio de Janeiro: Forense Universitária, 2008-A. Introduction à l'Anthropologie in Kant. I. Anthropologie d'um point de vue pragmatique, Vrin, Paris, 2008-B.

- Sur la sellette. In: FOUCAULT, Michel. Dits et écrits II (électronique). Paris: Gallimard, 2010.

FINK, Eugen. A filosofia de Nietzsche. Trad. Joaquim Lourenço Duarte Peixoto. Lisboa: Presença, 1983.

FREITAS, Augusto Teixeira de. Código Civil - Esboço. Rio de Janeiro: Typographia Universal de Laemmert, 1860.

GAILLARD, Emanuel. Le Pouvoir en Droit Privé. Economica, Paris, 1986.

GAMMON, Earl; PALAN Ronen, Libidinal International Political Economy, in DE GOEDE, Marieke (coord), International Political Economy and Poststructural Politics, Palgrave, Houndmills, 2006.

GRANOVETTER, Mark, SWEDBERG, Richard, The Sociology of Economic Life Westview Press, SAN FRANCISCO, 1992. 
GIACOIA Jr., Oswaldo. Sonhos e pesadelos da razão esclarecida: Nietzsche e a modernidade. Passo Fundo, RS: UPF, 2005.

. Nietzsche. Publifolha, São Paulo, 2000.

Esquecimento, memória e repetição, in Psicologia \& Sociedade; 13 (2):

58-91; jul./dez.2001.

GIAMETTA, Sossio, Colli e Montinari, Istituto Italiano Per Gli Studi Filosofici, Nápoles, 2007.

GRATZER, Karl, Introduction, in GRATZER, Karl, STIEFEL, Dieter (coord.), History of Insolvency and Bankruptcy from an International Perspective. Södertörns Högskola, 2008 .

GREABER, David. Debt : the first 5 ,000 years. New York: First Melville House Printing, 2011.

GROSSI, Paolo, Itinerarii dell'Impresa, in GROSSI, Paolo (ed.), Quaderni Fiorentini Per la Storia del Pensiero Giuridico Moderno, v. 28, Giuffrè, Milão, 1999. La Proprietà e Le Proprietà nell'Officina dello Storico, in Quaderni Fiorentini - Per la Storia del Pensiero Giuridico Moderno, v. 17, Giuffrè, Milão, 1988. HEGEL, Georg Wilhelm Friedrich. Princípios de Filosofia do Direito. Tradução Orlando Vitorino. São Paulo: Martins Fontes, 1997.

HENNIS, Wilhelm. Les traces de Nietzsche dans l'oeuvre de Max Weber. In : _. La Problématique de Max Weber. Paris: Presses Universitaires de France, 1986, pp.181-206. HABERMAS, Jurgen. O discurso filosófico da modernidade. Trad. Luiz Sérgio Repa e Rodnei Nascimento. São Paulo: Martins Fontes, 2002.

HAYEK, Friedrich A. The Constitution of Liberty. Chicago : Chicago University Press, 1978.

IRTI, Natalino. L'ordine giuridico del mercato. $2^{\mathrm{a}}$ ed, Laterza, Roma, 2003. Nichilismo Giuridico. Sagittari Laterza, Roma-Bari, 2005.

JAMES, Ian. The Fragmentary Demand: An Introduction to the Philosophy of Jean-Luc Nancy. California Stanfordp University Press, 2006.

JHERING, Rudolf von, Études Complémentaires de l'Esprit du Droit Romain I (trad. O. de Meulenaere), Aîné Marescq Editeur, Paris: 1880.

KANT, Immanuel. Crítica da Razão Pura. Trad. Valerio Rohden e Udo Baldur Moosburger. In: Coleção os Pensadores. São Paulo: Editora Nova Cultural Ltda, 2005. 
KENNEDY, David, Some Caution about Property Rights as a Recipe for Economic Development, in KENNEDY, David; STIGLITZ, Joseph, Law and Economics with Chinese Characteristics - Institutions for Promoting Development in the Twenty-First Century, Oxford University Press, Oxford, 2013.

A World of Struggle How Power, Law, and Expertise Shape Global Political Economy, Princeton University Press, Princeton, 2016.

KELSEN, Hans. Society and Nature - A Sociological Inquiry. The University of Chicago Press, Chicago, 1947.

Teoria Pura do Direito. Trad. João Baptista Machado. Martins Fontes, São Paulo, 2003.

KLOSSOWSKI, Pierre. Monnaie vivante. Payot \& Rivages, Paris, 1997-A. Nietzsche and the Vicious Circle. Trans. Daniel W. Smith. Chicago: The University of Chicago Press, 1997-B. Sade mon prochain précédé de Le philosophe scélérat. Paris: Seuil, 1967.

KOROBKIN, Donald R. Bankruptcy Law, Ritual, and Performance. Columbia Law Review, Vol. 103, No. 8, Columbia Law Review Association, 2003.

KOSSOVITCH, Leon. Gilles Deleuze, Francis Bacon. REVISTA USP, São Paulo, n.57, p. 160-168, março/maio 2003.

LARENZ, Karl. Metodologia da Ciência do Direito. Trad. José Lamego. $3^{\text {a }}$ ed., Calouste Gulbenkian, Lisboa, 1997.

LAZZARATO, Maurizio. The making of Indebted Man. An Essay on the Neoliberal Condition. Trad. Joshua David Jordan. MIT Press, 2012.

LEBRUN, Gerard. O avesso da Dialética: Hegel à Luz de Nietzsche. Trad. Renato Janine Ribeiro. São Paulo: Companhia das Letras, 1988.

LEITER, Brian. Nietzsche and the Morality Critics. Oxford: Oxford University Press, 2007.

LEVRATTO, Nadine, Abolition de la contrainte par corps et évolution du capitalisme au 19ème siècle, in Economie et Institutions, vol. 8, n 2, 2009.

LYOTARD, Jean-François. Heidegger e os Judeus. Petrópolis: Vozes, 1994. . Libidinal Economy. Translated by lain Hamilton Grant. Indiana: Indiana University Press, 1993. 
A Condição pós-Moderna. Trad. José Olympio. Rio de Janeiro,

2004.

LOSURDO, Domenico. Nietzsche, il ribelle aristocratico - Biografia intellettuale e bilancio critico. Bollati Boringhieri, Torino, 2004.

MARTON, Scarlett (Org.). Nietzsche hoje?. São Paulo: Editora Brasiliense, 1985.

Nietzsche - Das Forças Cósmicas Aos Valores Humanos, editora brasiliense, São Paulo, 1990-A.

Nietzsche e a Revolução Francesa. Discurso; Revista do

Departamento de Filosofia da USP, São Paulo (18):85-96, 1990-B.

MAUSS, Marcel. The Gift: Forms and Functions of Exchange in Archaic Societies. Norton Library, 1967.

MAZEAUD, Henri; MAZEAUD, Jean; MAZEAUD, Léon; JUGLART, Michel;

CHABAS, François, Leçons de Droit Civil - Introduction à l'Étude du Droit, Leçon de Droit Civil, $1^{\mathrm{o}}$ Tomo, Vol. 1, Montchrestien, Paris, 2000.

MONTESQUIEU. O Espírito das Leis. Trad. Cristina Murachco. São Paulo: Martins Fontes, 2000.

MONTINARI, Mazzino. Che Cosa ha Detto Nietzsche. Milão: Adelphi Edizioni, 1999.

NANCY, Jean-Luc. Corpus. Nova Iorque: Fordham University Press, 2008. Ego Sum. Flamarion, 1979. Le Sens du monde. Paris: Galilée, 1993.

NIETZSCHE, Friedrich W. Friedrich Nietzsche: Sämtliche Werke. Kritische Studienausgabe, (KSA) 15 volumes. Editado por Giorgio Colli e Mazzino Mortinari. Berlin, Walter de Gruyter, 1988.

NOBRE, Renarde Freire. Cultura e Perspectivismo nas visões de Nietzsche e Weber. Teoria \& Sociedade, 2005, número especial, pp.68-89. Weber e o desencantamento do mundo: uma interlocução com o pensamento de Nietzsche. Dados, 2006, vol.49, nº.3, pp.511- 536.

PARETO, Vilfredo. Systèmes Socialistes. Cours professé à l'université de Lausanne. Tomo II, Giard e Brière, Paris, 1902.

PLANIOL, Marcel, RIPERT, Georges, Traité Elémentaire de Droit Civil, Vol. 2, LGDJ, Paris, 1926.

PORTALIS, Jean-Étienne-Marie, Discours préliminaire du premier projet de Code civil, in Des Observations des Tribunaux D'Appel et du Tribunal de Cassation Sur le Projet de Code Civil, Éditeur Crussaire, 1802-A. 
Sur L'Organisation des Cultes, in Discours du Portalis, Le Clere,

Paris, 1802-B.

POTHIER, Robert-Joseph. Traité des Obligation, in Euvres de Pothier. Tomo 2, Cosse bt N. Delamotte, Paris, 1848.

ROBESPIERRE, Maximilien, Discours Sur Le Parti A Prendre à l'Égard De Louis XVI in ROBESPIERRE, Maximilien, Euvres, Tomo 3, Faubourg Saint-Denis, Paris, 1840.

ROPPO, Enzo. O Contrato, Trad. Ana Coimbra e M. Januário C. Gomes. Coimbra: Almedina, 1988.

ROUBINI, Nouriel; MIHN, Stephen. Crisis economics: a crash course in the future of finance. New York, Penguin Press, 2010.

SGARD, Jérôme, Bankruptcy Laws: Part of Global History, in Debin Ma et-Jan Luiten van Zanden, Law and Long Term Economic Change: An Eurasian Perspective, Stanford University Press, 2011.

SMITH, Adam, The Theory of Moral Sentiments. Cambridge University Press, Cambridge, 2002.

STATEN, Henry. A Critique of The Will To Power. In A Companion to Nietzsche, 2006. STEGMAIER, Werner. Orientierung im Nihilismus - Luhmann meets Nietzsche. Walter de Gruyter GmbH, Berlin/Boston, 2016. . Subjects as Temporal Clues to Orientation: Nietzsche and Luhmann on Subjectivity. In Bartholomew Ryan, Maria Joao Mayer Branco \& João Constancio (eds.), Nietzsche and the Problem of Subjectivity. De Gruyter. pp. 487-510, 2015.

STENGERS, Isabelle. A Invenção das Ciências Modernas. Trad. Max Altman, $1^{\mathrm{a}}$ ed, Editora 34, São Paulo, 2002. La guerre des sciences. Paris: Synthélabo, 1996

THALLER, Edmond. Des Faillites en Droit Comparé. Primeiro Tomo, Arthur Rousseau Editeur, Paris, 1887.

THÉRET, Bruno, Saisir les Faits Économiques: La Méthode Commons, in Cahiers d'économie Politique, L'Harmattan, 2001.

TEIXEIRA DE FREITAS, Augusto, Código Civil-Esboço, Rio de Janeiro, Typographia Universal de Laemmert, 1860.

TURGOT, Anne Robert Jacques. Euvres de Turgot., Tomo 1, Guillaumin Libraire, Paris, 1844.

VANEIGEIM, Raoul. A arte de viver para as novas gerações. São Paulo: Editora Conrad, 2002. 
VAN WETTER, P. Les Obligations en Droit Romain. A. Durand et Pedone-Lauriel, Paris, 1883.

VIVEIROS DE CASTRO, Eduardo. Metafísicas Canibais: Elementos para uma antropologia pós-estrutural. São Paulo: Cosac Naify, $1^{\text {a }}$ ed., 2015. Inconstância da Alma Selvagem e outros ensaios de antropologia.

São Paulo: Cosac Naify, 2002.

WALLERSTEIN, Immanuel, The Modern World System - Capitalist Agriculture and the Origins of the European World-Economy in the Sixteenth Century, Academic Press, Nova Iorque, 1974.

, The Modern World-System III, The Second Era of Great Expansion of the Capitalist World-Economy, 1730-1840s, Academic Press, San Diego, 1989; , The Modern World-System IV, Centrist Liberalism Triumphant, 17891914, University Of California Press, Los Angeles, 2011.

WIEACKER, Franz. História do Direito Privado Moderno. 2a ed. Almedina, Coimbra, 1995.

ZACHARIAE, C. S. (trad. Frédéric Charles Rau e Charles Aubry). Cours De Droit Civil Français. Tomo I, Meline Cans et Comp., Bruxelas, 1850. 